\title{
Anabases
}

ANABASES Traditions et réceptions de l'Antiquité

$4 \mid 2006$

Varia

\section{Luciano CANFORA, Il papiro di Dongo}

\section{Corinne Bonnet}

\section{OpenEdition}

\section{Journals}

Édition électronique

URL : http://journals.openedition.org/anabases/2855

DOI : 10.4000/anabases.2855

ISSN : 2256-9421

\section{Éditeur}

E.R.A.S.M.E.

\section{Édition imprimée}

Date de publication : 1 octobre 2006

Pagination : 302-304

ISSN : 1774-4296

\section{Référence électronique}

Corinne Bonnet, "Luciano canfora, II papiro di Dongo », Anabases [En ligne], 4 | 2006, mis en ligne le 01 mai 2012, consulté le 22 septembre 2020. URL : http://journals.openedition.org/anabases/2855 ; DOI : https://doi.org/10.4000/anabases.2855

Ce document a été généré automatiquement le 22 septembre 2020

(c) Anabases 


\title{
Luciano CANFORA, Il papiro di Dongo
}

\author{
Corinne Bonnet
}

\section{RÉFÉRENCE}

Luciano CANFORA, Il papiro di Dongo, Adelphi, L'oceano delle storie 7, Milan, 2005, 812 p.

32 euros / ISBN 88-459-2007-0.

1 L'histoire que nous raconte Luciano Canfora a pour cadre le monde académique italien et son attitude face au fascisme ; elle a pour héros trois «personnages » : un papyrus et deux savants, un homme et une femme, Goffredo Coppola (1898-1945) et Medea Norsa (1877-1952), aux destins radicalement différents, sur fond de guerre. C'est une fresque que dessine Canfora, où apparaît l'ensemble du monde intellectuel de l'époque, en Italie, mais pas seulement: Vitelli, Pasquali, Romagnoli, Vogliano, Breccia, Gentile, Croce, Bartoletti, mais aussi Cumont, Mazon...

2 Canfora retrace d'abord le parcours universitaire de Coppola et le situe dans un milieu universitaire, entre Naples, Florence et Bologne, où la papyrologie est en plein essor et génère un climat de vive compétition entre les grandes collections universitaires. Achille Vogliano, personnage trouble s'il en est, ambitieux et fuyant, attise les convoitises, tout en songeant essentiellement à sa propre carrière. Dans ces années-là, en 1931, le fascisme impose aux universitaires italiens le serment fasciste qu'une poignée seulement refuse. Le climat intellectuel se fait lourd. Au printemps 1933, sans doute, Franz Cumont acquiert au Caire un papyrus qui contient des fragments des Ploutoi de Cratinos, pris d'abord pour des fragments d'Aristophane. Vitelli, Vogliano, Mazon et Collart sont de suite mis dans le coup : la correspondance de Cumont permet de suivre le dossier de jour en jour. Il s'agit en effet d'un papyrus volé, issu des fouilles d'Evaristo Breccia à Oxyrrhinque, dont un autre fragment est entre les mains de Girolamo Vitelli. Canfora reconstruit tous les tenants et aboutissants de cette singulière partie de poker entre spécialistes qui débouche sur des transcriptions et des publications concurrentes. Vitelli et Norsa font paraître la première étude, bientôt 
suivie par celle de Mazon et les asceptiques échanges de tirage à part semblent tirer un trait sur cet embrouillamini papyrologico-diplomatique.

3 L'affaire rebondit cependant et Canfora bâtit, sur les traces de cette intrigue, une enquête policière absolument passionnante. Coppola entre sur la scène : il salue, avec emphase, dans le journal fascite Il popolo d'Italia, le 25 janvier 1934, la parution des nouveaux fragments et la qualité du travail accompli par les papyrologues florentins. Au même moment, cependant, Vogliano, dans une "scellerata intervista », objet du chapitre IV, parue quelques jours auparavant dans le même journal, s'était efforcé de minimiser le rôle de l'école de Vitelli-Norsa et de grandir celui de l'université de Milan. Ce n'est là qu'un épisode, mais non des moindres, d'une authentique «bataille » papyrologique, et archéologique, qui enflamme l'Italie sur fond de propagande politiconationaliste puisque, au-delà des oppositions d'écoles et de personnes, l'Italie entend se présenter comme une avant-garde intellectuelle et utilise diverses tribunes, les journaux en particulier, pour mettre en scène ses avancées.

4 La découverte des Helléniques dits d'oxyrrhinque, d'une part, du commentaire de Callimaque provenant de Tebtunis, d'autre part, s'insèrent précisément dans ce cadre : découverts par Breccia, ils aboutirent sur le marché des antiquités et furent « récupérés » en mains italiennes, grâce à la clairvoyance de Medea Norsa. Pour mieux comprendre les parcours, décidément troubles, que suivent les papyrus sortis de terre, Canfora dresse une fresque à la fois gigantesque et minutieuse, avec, à l'avant-plan, les Dioscures de la papyrologie, Grenfell et Hunt, et, sur le devant de la scène italienne, Coppola, toujours à l'affût des nouveautés, fidèlement attaché à l'école florentine. C'est lui qui hérite des Helléniques, morceau de choix, dont la publication lui est confiée par Vitelli, au grand dam de Vogliano qui avait eu ce document entre les mains et espérait qu'il lui fût réservé.

5 Canfora retrace alors l'histoire d'une édition qui tarde à voir le jour. Coppola, qui entretient des rapports féconds avec Gaetano De Sanctis, avait pris l'engagement de publier les fragments des Helléniques pour 1935, l'année de la mort de la Vitelli, par ailleurs. Mais Coppola a d'autres choses en tête : son engagement fasciste le distrait de ses devoirs de papyrologue, mais ne l'empêche pas de publier, en 1936, le premier tome de son Teatro di Aristofane. C'est alors qu'entre en scène Alberto Graziani, qui fait ses études à Bologne et se lie alors à Coppola, lequel sous-traite, auprès de ce jeune très prometteur, l'édition des Helléniques. Le projet de Coppola prévoit une publication de l'étude de Graziani dans une nouvelle revue, Sileno: Graziani termine son travail en 1936, des épreuves circulent, mais la revue ne paraîtra jamais et Graziani change d'orientation, attiré par l'histoire de l'art (il mourra en 1943). L'édition des Helléniques somnole et Medea Norsa a beau s'agiter : Coppola a d'autres chats à fouetter.

61938 marque le début, en Italie, des persécutions racistes, qui vont notamment frapper Medea Norsa, dont le père était juif et qui s'apprêtait à se rendre en Égypte pour une nouvelle mission scientifique qui n'eut jamais lieu.

7 Il est impossible de rendre compte ici des tous les méandres d'une enquête absolument passionnante, ponctuée par d'innombrables documents inédits. Les enjeux, le décor historique et les personnages ont été présentés : le lecteur suivra leur destinée avec gourmandise, tant le livre de Canfora est un régal pour l'esprit. On verra donc comment le papyrus fut finalement publié par Coppola dans un journal fasciste, comment il disparut durant la guerre pour réapparaître ensuite et se trouva au centre de tiraillements et de luttes de pouvoir au sein des universités italiennes, emblème d'un 
après-guerre encore marqué par les blessures et les divisions du fascisme ; on suivra les destins parallèles et opposés de Coppola, d'une part, totalement engagé dans le fascisme au plus haut niveau, fanatique parmi les fanatiques, très proche du nazisme, fusillé à Dongo avec la hiérarchie fasciste en fuite, et de Medea Norsa, d'autre part, image d'une vaillante résistance intellectuelle et illustration douloureuse des préjugés racistes et sexistes d'une génération d'académiques tiraillée entre ambitions, compromis et repli sur soi-même. C'est une saison intellectuelle dramatique qu'illustre ce livre, une saison brillante et pitoyable à la fois. Les fragments du papyrus de Dongo, sous la plume alerte de Canfora, deviennent dès lors un symbole ou les « cailloux du petit Poucet ", permettant au lecteur de parcourir une infinité de chemins, qui sont autant de niveaux de lecture d'un ouvrage vraiment important pour l'histoire intellectuelle des années ' 30 et ' 40 , voire au-delà, qui se lit au demeurant comme un Agatha Christie !

\section{AUTEURS}

\section{CORINNE BONNET}

Université de Toulouse II-Le Mirail

cbonnet@sfr.fr 